\title{
LXXXIII. Description of an œconomical culinary stove
}

\section{Rich. P. Player Esq.}

To cite this article: Rich. P. Player Esq. (1817) LXXXIII. Description of an œconomical culinary stove , Philosophical Magazine Series 1, 49:229, 354-359, DOI: $10.1080 / 14786441708637922$

To link to this article: http://dx.doi.org/10.1080/14786441708637922

曲 Published online: 27 Jul 2009.

Submit your article to this journal ๘

Џ Article views: 3

Q View related articles ¿ 
gative electricity of Franklin, and the element of light, or photogen, are only different names for the same thing.

And the fire-air of Scheele, the dephlogisticated air of Priest-: ley, and the oxygen gas of Lavoisier, are only different names for the same gas; the elementary or imponderable part of which is the same as the positive electricity of Franklin, and the element of heat, or thermogen.

That one of these is the element of light, and the other the element of heat, may be demonstrated thus: The gas procured from coals, with which the streets of large towns are now illuminated, contains the element of light. This element produces a most brilliant light with very little heat, as it consumes only a small quantity of the oxygen gas of the air. That the oxygen gas of the atmosphere contains the element of heat, may be clearly understood from the use of the blowpipe. This instrument produces the most intense heat, without increasing the light of the lamp; and the same effect is produced by other blowing machines used to increase the heat of furnaces.

Scheele observes in his. Treatise on air and fire ${ }^{*}$; that ${ }^{66}$ phlogiston is a true element and a simple principle, which enters into so close and subtle an union with empyreal or fire-air that it even penetrates through the most subtle pores of all bodies.

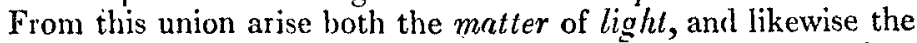
matler of heat $\uparrow$. In all these compositions phlogiston undergoes not the least change; and from the last composition it can he separated again. Phlogiston can by no means be obtained by itself; for it never separates from one body, though united with it ever so closely, unless there be present another coming in immediate contact with it."

Hence the term phlogiston, which has been so much animadverted upon by chemical philosophers, is only another name for that inflammable element contained in a certain class of bodies, and this s perhaps as proper a name as any other that has yet been invented.

Lynn, May 12, 1817.

Ezekiel Walkek.

[To be continued.]

LXXXIII. Description of an cecononical culinary Stove. By Rich. P. Player, Esq. Malmsbury.

To Mr. Tilloch.

Sra, - A corruspondent in your Number for November last has proposed some inquiries respecting the most oconomical

* Page 103 .

t The elcments of light and heat are very different from the matler of light and the matler of hcat. This very important subject still reuaitus for iurestigation. 
construction of an oven for baling, \&c. and an apparatus fot heating liquids and drying substances by stcan. Having had a simple, and by no means expensive, culinary store for more than a year in constant use in my own kitchen, which was constructed without a knowledge of or reference to any other of a similar kind, is very ceconomical with respect to fuel, and unites great convenience and cleanliness with extent of application, I have thought a description of it neay be worthy of your notice. It has been adopted by several of ny neighbours, who have expressed themselves much pleased with it; and though the description coes not completely solve the inguiries suggested, it may be useful to your correspondent, or others who nay choose to make trisl of one of a similar construction.

It is extremely probable that somorhing similar to the apparatus I am about to describe may hare been emplosed by others; but the skilful direction of heat from a small guantity of fire to our various culinary and domestic purposes is by no means generally understood; and notwithstanding the exertions of Count Rumford and others, the attention of men of science, to this interesting and useful subject will most probably be still repaid with valuable improvements. I venture to hope, theretore, that the present communication will not be withont its use in cortributing to improve our domestic ueconony, and diminishine that wasteful consumption of fuel mavoidable in conductiug culinary and domestic processes by an open fire.

The stove which I am now to submit to your notice projects in front of the ordinary fire-place, which has been buit up, the necessary communications with the chinney being preserved.

The fire-place of the stove is built of bricks; it is nine inches long in the grate, six inches wide, and seven inches deep. The grate is situated four inches nu a balf from the door, and the interval is covered with a plate of iron. The frout of the stove as far as the side wall of an oven on the right is covered with a plate of sheet-iron 1 -Sth of an incly thick, in which the doorways are cut, and which is secured by stavs walled into the brict:work. Over the top of this fire-place a cast-iron plate is lati twenty inches square and 3-Sths of an inch thick.

From the top of this fire-place a fue for the passage of the heated air passes under the oven, then up the side furthest from the fire till it reaches the top, whence it descends down the back of the oven to the bottom of the side next to the fire, and is continued up that side, and then along the top to the centre, where its escape into the chimney is regulated by a sliding register.

The width of the flue round the oven should be about three inches in the part under the oven, and two inciles and a half up the side furthest from the fire; the space $x+$ the bats of the 72 
oven, which serves for the descent of the hot air, should also be about two inches and a half wide, and likewise that part by which the hot air ascends, seeking its way to the chimney. Tlie other dimension, or the depth of the flue, depends on the size of the oven, the flue being of the whole depth of the oven excepting only the thickness of the brick-work in front, which should not exceed three inches, that the quantity of surface exposed to the hot air may be as little reduced as possible.

The oven which I have adopted is about fourteen inches wide, twelve high, and sixteen deep from front to back, which will be found convenient dimensions for moderate families.

Moveable stoppers are inserted in the brick-work for the convenience of eleaning the flue-one of these, placed at the back corner parallel to the bottom of the oven and top of the fireplace, serves for sweeping out the flie at the bottom, at the back of the oven, and up the side next the fire-place; another at the front bottom torner, furthest from the hire-place, serves for cleaning the ascending flue furthest from the fire ; and a third in front over the door of the oven for cleaning the top part of the fiue. A door, closed with sheet-iron, opens into the chim ney, over the fire-place, for sending up a sweep to clean the chimney.

At the distance of about three feet over the stove, there is a horizontal frame of wood about four feet long by twenty inches wide, having wires or strings from cul to end, three or four inches apart, for drying linen, \&c. 'This frame, by means of a pair of hinges, may be turned back against the wall when not in use.

By this simple apparatus, the various processes of boiling, steaining, roasting, baking, \&c. can be conducted on an extensive scale with the greatest ease and in the most cleanly manner, with a quantity of fuel so small as to be scarcely credited by those accustomed only to open fires, and with what are called smallcoals, which can be purchased here at about two-thirds of the price of the mixed or large and small together. The same fire which heats the cast-iron plate sufficiently for boiling, steaming, $\mathrm{Bc}$, at the same time heats the oven for roasting or baking.

The kitchen is completely warmed in the coldest weather, and can be readily vertilated in summer. Linen, \&c. is dried and aired with great rapidity, and flats are heated for ironing. The oven being constantly hot is found useful for various purposes, and when not otherwise wanted, is kept open, or shut, as more or less heat in the kitchen is required. On its top, plates and dishes are warmed for the table, or liquirds may be kept at a moderate heat for any length of time. When the fire is not wanted, it may be kept in for several hours, by nearly closing the registers, with very little consumption of fuel, and may be blown up in a few minutes by opening them. 
Boiling, steaming, and frying, are conducted on the cast-iron plate over the fire-place. One of the size above described, twenty inches square, is large enough for most moderate families; for, when a vessel is made to boil by being placed on the hot test part, it may be removed to one side, where it will keep boiling for any length of time; and another which is required to boil may be wibtituted in its place.

In families where large quatities of hot water are wanted, a boiler may be set on one side of the cast-iron plate and an oven on the other,-but this will not in general be found necessary.

Persons accustomed to place their vessels over the irregular surface of an open fire, or on the hooks and other contrivances made use of to support them, will be surprised at the great steadiness and cleanliness with which the process of boiling is conducted on an iron plate.

Steaning may be conducted immediately over the vessels of boiling water, or in others at a distance; or the steam, confined between the sicles of double metallic vessels of various forms, may be applied to the purposes of warming water, drying, \&c.

The bottoms of vessels used for boiling on an iron plate should be perfectly flat; and both these, and those used for steaming, should have their sides and tops kept as bright as possible

The boiling temperature in liquids, except the plate be very hot, is not obtained quite so soon as over an open fire; but this will he found productive of little or no inconvenience, as the vessel has only to be placed on it somev?hat e:rlier.

The common frying-pan may be used over an iron plate; hut one with deeper sides would be preferable, to prevent the fying over of any particles of fat, which should be carefully avoided, both on the plate and in the oven.

Bread may be toasted by being cut with a smooth suriace, and placed on a small wire frame laid on the iron plate, so close as uist to prevent its contact. Small picces may also be toasted in the fire place, and steaks, \&c. may be readily broiled therein, on a gridiron adapted to its form and size.

Cheese may be toasted with much greater facility than before a fire, by being placed on the stove in a common plate, and turned once over.

That roasting can be well conducted in an oven, is liy no means generally known. The difference between it and baking is this, that the latter process is performed, as your correspondent suggests, with the door closed; and the former, with it sufficiently open to admit of a gentle current of air passing constantly through the oven: and as in every oven, when the door is open, a current of cold air enters near the bottom, and, passing round up the back, returns out highly hoated under its top, it is necesZ3 
sary to place the meat in this upper current of air. The oven door may be kept quite shut till the meat is warmed through, and begins to roast; and then should be opened about the width of oneeighth of an inch in front, or wider if the processs goes on too rapidly. The meat should be turned and dripped occasionally; and generally requires about one-third more time than when roasted before a fire; from which, however, when the process is conducted with moderate care, it cannot be distinguished by the nicest taste.

As the lower current of air tends to preserve the dripping-pan cool, placing it in another containing water, as described by Count Rumford, will not be found necessary after a little practice in regulating the heat of the oven by the registers.

It is obvious that one of Count Rumford's roasters, or roasting ovens, may be heated by the flue from the fire-place, as well as a common cast-iron oven; but as the former in particular are much more expensive, more complex, and less durable-and as the process of roasting can be conducted in the highest perfection in a common cast-iron oven, this, in families where cheapness and simplicity are kept in view, will obtain the preference.

The oven might be constructed of sheet-iron at a trifling expense, and would never be liable to injury from the fire, at the distance at which it is placed. Even an old cast-iron pot, placed sideways, with a wooden stopper, would make no contemptible oven; and with a cast-iron plate, a fre-place door, and a few bars, a stove might be cheaply constructed in those situations of life where comfort and oeconomy are more particularly desirable.

As the temperature of the oven can be varied at pleasure, by urging the fire more or less, by keeping its door shut or open, and in the latter case by placing the article to be subjected to the effects of heat higher or lower, it forms of itself a small drying stove; and when in addition to it the iron plate on its top, and that over the fire-place, are taken into consideration, it is obvious that any degree of temperature up to red heat can be always obtained; and in the current of warm air inmediately over the stove, when drying at a lower temperature is reçuired, it can be conducted with great ease, and on a more extensive scale.

It will be observed, that the fire-place is not situated immediately und $r$ the centre of the iron-plate, but at the distance of ahout nitse inches trom its left-hand edige, which, allowing six inches for the wirlth of the fire-place, leaves about five inches in the clear between it and the sige-wall of the oren. The object of thas whing it towards the oven is, that too much of the heat mat son se expended under the plate, but that a due share of it maty be nts arted around the oven.

If in: however, be placed inmediately under the centre of the plate, in which wasc the entrance from the fire-place into the 
first fine (which in the present construction is over the upright side of the fire-place) should be made sloping upwards from near its bottom.

It will be found convenient to have a strip of iron plate, three or four inches wide, riveted to the right-hand edge of the castiron plate, and turned up at a right angle against the side of the oven-flue, as the mortar is liable to crack with the strong heat, and to be struck off by the culinary vessels.

Once in three or four days a little straw, or a few shavings or sticks of brush-wood, should be kindled in the fre-place, and suffered to bum freely for a few minutes with the dampers open, to clear the flues of soot, which would otherwise collect and impede the passage of the smoke. With this precaution, the stoppers, which are left for cleaning then, will only require to be withdrawn once in a quarter of a year or longer, to remove the ashes of the sont, which is readily done with a brush having a flexible wire handle.

If at any time, for want of burning out, the flues should get so full of soot as to impede the current of the smoke, which only happens from inattention, it may be casily broken down by introducing the brush, and then burnt, without the trouble of sweeping it out.

The high price of what are called the steam litulueus, their complex structure, and the frequent repairs some of them stand in need of, together with the disculty of heating boilers, cvens, $8 \mathrm{c}$. weconomically, from an open tire, even were the flues which surround their sides constructed in the most advantigeous manner, are objections to their general adoption; not to mention the smoke, soot, and dust of open fires, and the more extensive application to the purposes of drying and warming of which a stove is capable.

I fear I may have trespassed on the patience of some of your readers by descending too much into detail on a humble subject; but I trust to their candour for excuse, when it is considered that my observations are ultimately for the use of persons in the humbler situations of life; that our culinary processes are, even at this culightened period, commonly condurted with scarcely more skill in the application of heat, than they were by our aboriginal ancestors; that individuals accustomed always to open fires are likely at first to experience occasional embarrassment in the direction of its unseen energies in a more artificial manner; and that the highest speculations of science, however gratifying to our vanity, are comparatively of little value till they are made subservient to our necessities. I am, sir,

\section{Your obedient servant,}

Malmsbury, Dec. 10, 1816.

Rich. P. Player. 